\title{
Development of a stem taper equation and modelling the effect of stand density on taper for Chinese fir plantations in Southern China
}

Aiguo Duan, Sensen Zhang, Xiongqing Zhang, Jianguo Zhang

Chinese fir (Cunninghamia lanceolata) is the most important commercial tree species in southern China. The objective of this study was to develop a variable taper equation for Chinese fir, and to quantify the effects of stand planting density on stem taper in Chinese fir. Five equations were fitted or evaluated using the diameter-height data from 293 Chinese fir trees sampled from stands with four different densities in Fenyi County, Jiangxi Province, in southern China. 183 trees were randomly selected for the model development, with the remaining 110 trees used for model evaluation. The results show that the Kozak's, Sharma/Oderwald, Sharma/Zhang and modified Brink's equations are superior to the Pain/Boyer equation in terms of the fitting and validation statistics, and the modified Brink's and Sharma/Zhang equations should be recommended for use as taper equations for Chinese fir because of their high accuracy and variable exponent. The relationships between some parameters of the three selected equations and stand planting densities can be built by adopting some simple mathematical functions to examine the effects of stand planting density on tree taper. The modelling and prediction precision of the three taper equations were compared with or without incorporation of the stand density variable. The predictive accuracy of the model was improved by including the stand density variable and the mean absolute bias of the modified Brink's and Sharma/Zhang equations with a stand density variable were all below $1.0 \mathrm{~cm}$ in the study area. The modelling results showed that the trees have larger butt diameters and more taper when stand density was lower than at higher stand density. 
1 Development of a stem taper equation and modelling the effect of stand density on taper for Chinese fir plantations in Southern China

$9 \quad *$ Corresponding Author: zhangig@,caf.ac.cn

Research Institute of Forestry, Chinese Academy of Forestry

Haidian district

Beijing 100091

P.R.CHINA

Tel: 86-10-62888309

Fax: 86-10-62872015 
24 Abstract

Chinese fir (Cunninghamia lanceolata) is the most important commercial tree species in

southern China. The objective of this study was to develop a variable taper equation for Chinese

fir, and to quantify the effects of stand planting density on stem taper in Chinese fir. Five

equations were fitted or evaluated using the diameter-height data from 293 Chinese fir trees sampled from stands with four different densities in Fenyi County, Jiangxi Province, in southern

China. 183 trees were randomly selected for the model development, with the remaining 110 trees used for model evaluation. The results show that the Kozak's, Sharma/Oderwald,

Sharma/Zhang and modified Brink's equations are superior to the Pain/Boyer equation in terms of the fitting and validation statistics, and the modified Brink's and Sharma/Zhang equations should be recommended for use as taper equations for Chinese fir because of their high accuracy and variable exponent. The relationships between some parameters of the three selected equations and stand planting densities can be built by adopting some simple mathematical functions to examine the effects of stand planting density on tree taper. The modelling and prediction precision of the three taper equations were compared with or without incorporation of the stand density variable. The predictive accuracy of the model was improved by including the stand density variable and the mean absolute bias of the modified Brink's and Sharma/Zhang

41 equations with a stand density variable were all below $1.0 \mathrm{~cm}$ in the study area. The modelling 
43

44

45

46

47

48

5

lower than at higher stand density.

Keywords: Chinese fir; Taper equation; Tree form; Stand density; Modelling

6

7

\section{Introduction}

Chinese fir (Cunninghamia lanceolata) is the most common coniferous species in southern China, occurring in both naturally regenerated stands and plantations. According to the seventh Chinese National Forest Inventory, Chinese fir plantations occupied almost 8.54 million ha and have a standing stock volume of 620.36 million $\mathrm{m}^{3}$ as a dominant tree species (SFA, 2009). The estimation of individual tree volume for Chinese fir is often based on existing volume tables. Volume tables are needed to accurately estimate tree volume or merchantable timber volume at any stem diameter along the trunk in accordance with wood use in the industry through the use of compatible volume and taper equations (Kozak, 1988; Riemer et al., 1995; Bi, 2000).

A stem taper equation describes a mathematical relation between tree height and the stem diameter at that height. It is thus possible to calculate the stem diameter at any arbitrary height and conversely, to calculate the tree height for any arbitrary stem diameter. Consequently, the stem volume can be calculated for any log specification and a volume equation can be developed for classified product dimensions. Numerous and various mathematical taper functions have been developed in attempts to describe tree taper. Viewed from the structures of these equations, the different taper equations can be divided into three major categories: simple mathematical 
64

equations (Kozak et al., 1969; Reed and Byrne, 1985; Pain and Boyer, 1996; Sharma and Odervald, 2001), segmented taper equations, represented by Max and Burkhart (1976), Brink and Gadow (1986), Clark et al. (1991), Gadow and Hui (1998), Brook et al. (2008) and Cao and Wang (2011), and variable-exponent taper equations, the latter being introduced by Newberry and Burkhart (1986), Kozak (1988; 1997; 2004), Newnham (1992), Riemer et al. (1995), Bi (2000) and Sharma and Zhang (2004). Research has shown that variable-exponent taper equations performed better than the other two types of equations, and were found to be the most accurate taper equations (Newnham, 1988; Kozak, 1988; Muhairwe, 1999; Sharma and Zhang, 2004; Rojo, 2005).

Some variables related to forest management have long been recognized such as planting density, fertilization, thinning and age (Gray, 1956; Bi and Turner, 1994; Palma, 1998; Sharma and Zhang, 2004). Some tree-level or stand-level indices (e.g., crown height, ratio, and site class) have been introduced into taper equations to improve modeling performance (Burkhart and Walton, 1985; Valenti and Cao, 1986; Newnham, 1992; Muhairwe et al., 1994; Özçelik et al., 2014). In contrast, stand density is more easily obtained; in addition, Sharma and Zhang (2004) introduced stand density information into a previously developed variable taper equation for Black Spruce and found improved fit statistics and predictive accuracy. Sharma and Parton (2009) further modeled stand density effects on taper for Jack Pine and Black Spruce plantations using dimension analysis, and reported that the difference in bole diameter between trees at lower and higher stand densities diminished as stand density increased. Gadow and Hui (1998) have developed a taper equation based on the modified Brink's function for Chinese fir plantations, 
85

86

87

88

89

90

91

92

93

94

95

but no attempt has been made to quantify the stand density effect on tree taper for Chinese fir.

The objective of this study was to develop a taper equation and quantify the effect of planting density on stem taper for Chinese fir in Southern China.

\section{Materials and methods}

\section{Data}

A total of 293 trees sampled from 12 plots of even-aged Chinese fir stands were used in the present study. The trees were taken from unthinned stands that were planted in 1981 for a density-effect study of Chinese fir in Fenyi County, Jiangxi Province, of southern China (Duan et al., 2013). A series of stand planting densities included densities of 1667 (A: $2 \times 3$ m), 3333 (B: $2 \times 1.5 \mathrm{~m}), 5000(\mathrm{C}: 2 \times 1 \mathrm{~m}), 6667(\mathrm{D}: 1 \times 1.5 \mathrm{~m})$, and $10000(\mathrm{E}: 1 \times 1 \mathrm{~m})$ stems/ha. Every planting density plot had three replications. A 2008 ice storm (Zhou et al., 2010) damaged or felled numerous trees in the trial plots. The sampled 293 trees were distributed in four kinds of planting densities: B, 50 trees; C, 78 trees; D, 84 trees; and E, 81 trees. Only five trees were felled in the A plots; therefore, these trees were excluded from the analysis. Two hundred and ninety three trees from different planting densities were divided into size classes based on diameter at breast height $(D)$, and random selection was then applied to each of size class for data splitting, with 183 trees selected for model development, and the remaining 110 trees used for model evaluation.

The total tree height $(H: \mathrm{m})$ and $D(\mathrm{~cm})$ were measured. Diameter outside bark $(\mathrm{cm})$ was also measured at heights of $0.2,1,1.3$, and $2 \mathrm{~m}$ and then at intervals of $1 \mathrm{~m}$ along the remainder of the stem. Table 1 summarizes the statistics related to tree characteristics. 


\section{Table 1 is here.}

107

Figure 1 shows a plot of diameter against relative height, which reflects the rate of decline

108

109

110

111

112

113

114

115

116

117

118

119

120

121

122

Figure 1 is here.

\section{Taper equations}

Five taper equations were analyzed in the present study, including two simple mathematical equations (Pain and Boyer, 1996; Sharma and Oderwald, 2001), one segmented and variableexponent taper equation (Riemer et al., 1995), and two variable-exponent taper equations (Kozak, 2004; Sharma and Zhang, 2004).

Brink and Gadow (1986) assumed that a tree form is composed of upper and lower parts, and developed a three-parameter equation for the whole stem taper:

$$
r(h)=b_{1}+\left(r_{1.3}-b_{1}\right) \cdot e^{b_{2}(1.3-h)}-\frac{b_{2} i}{b_{2}+b_{3}}\left(e^{b_{3}(h-H)}-e^{b_{3}(1.3-H)+b_{2}(1.3-h)}\right)
$$

where, $r(h)$ : stem radius $(\mathrm{cm})$ at height $h(\mathrm{~m}), h$ : tree height from the ground, $H$ : total height $(\mathrm{m})$, $r_{1.3}:$ stem radius at breast height, $b_{1}, b_{2}, b_{3}$ are parameters to be estimated.

Because equation (1) could not fulfill the condition that $r(h)$ is equal to zero when $h=H$,

Riemer et al. (1995) proposed the modified Brink's equation:

$$
r(h)=u+v \cdot e^{-b_{2} h}-w \cdot e^{b_{3} h}
$$


126 where, $u=\frac{b_{1}}{1-e^{b_{3}(1.3-H)}}+\left(r_{1.3}-b_{1}\right)\left(1-\frac{1}{1-e^{b_{2}(1.3-H)}}\right), v=\frac{\left(r_{1.3}-b_{1}\right) \cdot e^{1.3 b_{2}}}{1-e^{b_{2}(1.3-H)}}, w=\frac{b_{1} \cdot e^{-b_{3} H}}{1-e^{b_{3}(1.3-H)}}$ relative height, and developed a two-parameter taper model as follows:

$$
d(h)=b_{1}\left(1-\left(\frac{h}{H}\right)^{3}\right)+b_{2} \ln (h / H)
$$

where, $d(h)$ : diameter $(\mathrm{cm})$ at height $(\mathrm{m})$. compatible one-parameter taper equation:

$$
d^{2}(h)=D^{2}\left(\frac{h}{1.3}\right)^{2-\mathrm{b}_{1}}\left(\frac{H-h}{H-1.3}\right)
$$

where, $D$ : diameter at breast height. of the relative height $(z)$, and resulted in a variable-exponent taper equation, i.e.

$$
d^{2}(h)=b_{1} D^{2}\left(\frac{h}{1.3}\right)^{2-\left(b_{2}+b_{3} z+b_{4} z^{2}\right)}\left(\frac{H-h}{H-1.3}\right)
$$

138 where, $z=\frac{h}{H}, b_{4}$ is parameter.

where, $b_{4}, b_{5}, b_{6}, b_{7}, b_{8}, b_{9}$ and $p$ are parameters.

\section{Model development and evaluation with or without density variable}

Eqs. (2-6) were fitted first and then compared using fit data set including 183 trees to get the suitable taper equations for Chinese fir trees. Secondly, the fit and validation data set were 
146 the suitable taper equations from the first step were fitted and validated separately to each

147 density class. To evaluate the predictive ability of the equations over the whole bole, the relative

148 heights $(z)$ were divided into ten sections for each stand planting density. Thirdly, the density

149 variable was introduced into the selected taper equations through discussing the mathematical

150 relationship between the resulting coefficients and the density classes or building and adding a

151 stand density function to the exponents of the equations (Valenti and Cao, 1986; Sharma and

152 Zhang, 2004). Lastly, the suitable taper equations with density variable were separately fitted and

153 evaluated by the whole fit data set and the whole evaluation data set.

154 Model simulation and evaluation criteria

155 All the equations were fitted by the NLIN procedure in the SAS statistics program (SAS

Institute Inc., 2008). Multicollinearity is defined as a high degree of correlation among several independent variables. The existence of multicollinearity is not a violation of the assumptions underlying the use of regression, and therefore does not seriously affect the parameter estimates and the predictive ability of the equation (Myers, 1990; Kozak, 1997). Two general methods have been suggested to deal with continuous and multilevel longitudinal data. The first is to incorporate random subject effects (Gregoire et al., 1995), and the other is to model the correlation structure directly. In the present study the first method was adopted to test the simulation properties of the taper equations in the presence of autocorrelation. Figure 2 describes the error structure of Eq.(5) with or without random subject effects incorporated. It was found that the simulation result hadn't been obviously altered while considering autocorrelation.

Additionally, some studies had found that the Eqs. $(2,6)$ showed very low multicollinearity (Rojo 
167 et al., 2005; Kozak, 1997). So the correlated error structure in the data was not considered in the

168 SAS MODEL procedure.

169

170

171

172

173

174

175

176

177

178

179

180

181

182

183

184

83

Figure 2 is here.

The model adjusted coefficient of determinations $\left(R_{a d j .}^{2}\right)$, mean difference (bias: M.D.), mean absolute difference (M.A.D.) and standard error of estimate (S.E.E.) were examined while comparing modeling accuracy of the equations. These statistical indices can be calculated using equations $(7-10)$ :

$$
R_{a d j .}^{2}=1-\frac{\frac{1}{n-k-1} \sum_{k=1}^{n}\left(o b s_{k}-e s t_{k}\right)^{2}}{\frac{1}{n-1} \sum_{k=1}^{n}\left(o b s_{k}-\overline{o b s_{k}}\right)^{2}}
$$

where $o b s_{k}$ and $e s t_{k}$ are the observed and predicted diameter along the bole for the $k^{\text {th }}$ height point, respectively, $n$ is the number of height points along the bole, and $m$ is the number of equation parameters.

Results and discussion

\section{Without stand density}

Table 2 presents the fit statistics and parameters of Eqs. (2-6) using the fit data. Based on 
$185 R_{a d j .}^{2}$ and S.E.E., the Kozak equation, Sharma/Zhang, Sharma/Oderwald and modified Brink's

186 equations have higher precision than the Pain/Boyer equation. The S.E.E. of Kozak,

187 Sharma/Zhang, Sharma/Oderwald and modified Brink's equations were 0.5194, 0.5224, 0.5335

188 and 0.6629 , respectively. The results proved that the variable-exponent taper equations (Eq. (2, 5,

189 6)) all had the higher modelling precision than the simple mathematical taper equation (Eq. (3)).

190 And it's worth noting that the simple mathematical equation (Eq. (4)) also had high modelling

191 precision for Chinese fir tree's stem taper.

Table 2 is here.

The accuracy of diameter predictions by these five taper equations was evaluated along the

bole of Chinese fir trees using the validation data sets (Fig. 3). Diameter prediction bias of

Chinese fir trees for Eqs. $(2,4-6)$ was smaller than for Eq. (3). Obviously, the predicted diameter

corresponding to the section closest to the ground was generally underestimated for all of the

five equations. When compared with the Sharma/Oderwald and Sharma/Zhang equations, we

found the modified Brink's equation only had relatively low prediction precision at the butt

diameter. Except for the butt part, the accuracy of diameter predictions of the modified Brink,

Sharma/Oderwald and Sharma/Zhang equations showed a trend of decrease with the increase of

relative height, and the results from the three equations were very similar, with an average size of

error in diameter predictions below $0.2 \mathrm{~cm}$. For the Kozak equation, most of the predictions were

underestimated, especially corresponding to the lower stem, which led to this equation had a 
206 207 pine.

208

209

210

211

212

213

214

215

216

217

218

219

220

221

222

223

224

225

226

西

that parameter $b_{8}$ of the Kozak equation had not significance at the $95 \%$ test level for maritime

\section{Figure 3 is here.}

Based on the fitting and validation statistics, the Sharma Oderwald, Sharma/Zhang and modified Brink's equations are suggested for use as taper equations for Chinese fir trees. Figure 4 showed a simulation result of the three equations for a Chinese fir tree's stem taper. Besides the structural difference, the fact that the five taper equations use different sets of predictor variables may be an important reason for the differences in simulation accuracy. Eq. (2 and 4) use $D$ and $H$, together with $h$. Furthermore, Eq. (3) uses $H$ and $h$, but not $D$, Eq. (6) uses $D, H$ and the $z$, while Eq. (5) uses $D, H, h$ and also the $z$. Since $D$ is the most important factor for measuring tree size, ignoring this predictor variable may lead to the poorest performance of Eq. (3), the Pain/Boyer taper equation. In contrast, Eq. (5), the Sharma/Zhang taper equation, was shown to have the highest prediction accuracy because it included all important predictor variables (Fig. 3).

\section{Figure 4 is here.}

\section{Estimations that consider stand density}

Table 3 lists the estimated parameter values and the corresponding fit statistics of Eqs. (2,4-

5) for the density-grouped subsets of data. The estimates of most parameters of Eqs. $(2,4-5)$ were significantly different between the four planting densities $(p<0.0001)$. In the case of Eq. (5), however, only the estimates for $b_{2}$ were significantly different between any two of the four planting densities $(p<0.0001)$. The estimates for $b_{4}$ were significantly different between the four 
227

228

229

230

232

233

234

235

236

237

238

239

240

241

242

243

244

245

246

247

planting densities $(p<0.0001)$, and the estimates for $b_{1}$ were not significantly different between any two of the four planting densities $(p>0.3784)$. The estimates for $b_{3}$ were found having no significance at the $95 \%$ level. These comparisons were made based on the confidence limits of the parameters obtained by nonlinear regressions.

\section{Table 3 is here.}

To examine the effect of stand planting density on tree taper, the correlations between some parameters of Eqs. (2) and (4) and stand planting density were analyzed (Figure 5). The relationships of parameter $b_{1}$ of Eq. (2) and parameter $b_{1}$ of Eq. (4) to stand planting density were well approximated by both an exponential and a linear function. The coefficients of determination $\left(R^{2}\right)$ between parameter $b_{1}$ of Eq. (2) and Eq. (4) and stand planting density were 0.68 and 0.98 , respectively, and the test result of correlation coefficient showed that parameter $b_{1}$ of Eq. (2) and Eq. (4) were significantly related to stand planting density $(p<0.1$ and $p<0.01$, respectively). The other parameters all lacked obvious monotonic correlations to stand density. The results showed that stand planting density had an obvious effect on some parameters used in the taper equations. So, the resultant parameter prediction equation for predicting $b_{1}$ of Eq. (2) and Eq. (4) can be given by Eqs. (11) and (12).

$$
\begin{aligned}
& b_{1}=i_{1} \cdot s p d^{i_{2}} \\
& b_{1}=k_{1} / s p d+k_{2}
\end{aligned}
$$

where spd refers to stand planting density, and $i_{1}, i_{2}, k_{1}$ and $k_{2}$ are parameters to be estimated. Eqs. (11) and (12) can be substituted into Eqs. (2) and (4), and the Eqs. (13) and (14), including a stand planting density term, are then deduced. 
$248 \quad r(h)=\frac{i_{1} \cdot s p d^{i_{2}}}{1-e^{b_{3}(1.3-H)}}+\left(r_{1.3}-i_{1} \cdot s p d^{i_{2}}\right)\left(1-\frac{1}{1-e^{b_{2}(1.3-H)}}\right)+\frac{\left(r_{1.3}-i_{1} \cdot s p d^{i_{2}}\right) \cdot e^{1.3 b_{2}}}{1-e^{b_{2}(1.3-H)}} \cdot e^{-b_{2} h}-\frac{i_{1} \cdot s p d^{i_{2}} \cdot e^{-b_{3} H}}{1-e^{b_{3}(1.3-H)}} \cdot e^{b_{3} h}(13$

$249 \quad d^{2}(h)=D^{2}\left(\frac{h}{1.3}\right)^{2-\left(k_{1} / s p d+k_{2}\right)}\left(\frac{H-h}{H-1.3}\right)$

250 The test results of correlation coefficients showed that the parameters of Eq. (6) were found

251 not having significant relevance to stand planting density $(p>0.1)$. Sharma and Zhang (2004)

252 modified Eq. (6) to accommodate stand density effect by adding a stand density function to the

253 exponent of Eq. (6), i.e.:

254

$$
d^{2}(h)=b_{1} D^{2}\left(\frac{h}{1.3}\right)^{2-\left(b_{2}+b_{3} z+b_{4} z^{2}+b_{5} / s p d\right)}\left(\frac{H-h}{H-1.3}\right)
$$

To examine the effect of stand planting density on tree taper in a Chinese fir plantation, Eqs.

256

257

258

259

260

\section{Figure 5 is here.}

\section{Table 4 is here.}

Eqs. (13-15) were further evaluated using the validation data sets. The bias distribution ranges of Eqs. (13-15) with the density variable were -0.0556 to $0.7662,-0.2779$ to 0.02330 and -0.0983 to 0.1513 , respectively (Table 5). Clearly, adding the stand density variable improved the evaluation efficacy for Chinese fir trees (Table 6).

Table 5 is here.

Table 6 is here. 
of tree stems than at mid-stem. However, the Sharma/Oderwald and Sharma/Zhang equations

had larger bias at lower stem parts, and the Sharma/Oderwald equation had an almost negative

bias along the boles excepting at the butt. The results show that the diameters at two ends of the

stems of Chinese fir trees will be underestimated when using the modified Brink's equation, and

were mostly overestimated by the Sharma/Oderwald equation (Table 5).

The maximum mean absolute bias of the modified Brink's, Sharma/Oderwald and

Sharma/Zhang equations with the stand density variable were $0.7662,0.5498$, and $0.5161 \mathrm{~cm}$.

Note that the modified Brink's equation had relatively larger bias than the Sharma/Zhang and

Sharma/Oderwald equations only because of the great bias at the butt of tree stems. Considering the variable-exponent taper equation's theoretical property, the modified Brink's and

Sharma/Zhang equations were the most appropriate equations for describing tree taper of

Chinese fir trees.

The effect of stand planting density was analyzed visually by generating tree profiles using Equation (15) for $D=11.0 \mathrm{~cm}$ and $H=15.0 \mathrm{~m}$ at four different stand densities $(1000,2000,3000$, and 4000 trees/ha) (Figure 6). The results show that the trees have larger butt diameters and more taper when stand density was lower than at higher stand density. Additionally, the difference in bole diameter between trees at both lower and higher stand densities decreases as stand density increases. This phenomenon confirms the findings of Sharma and Zhang (2004) and Sharma and Parton (2009). However, except for the butt diameters, prediction diameters in the middle section only have weak differences among the different stand densities, which was different from a study 
290

291

292

293

294

295

296

298

299

300

301

302

303

304

305

306

307

308

309

310

of black spruce (Sharma and Zhang, 2004). The reason may lie in the difference between the two tree species. Sharma and Zhang (2004) found that density affected the taper of jack pine more than that of black spruce. Additionally, because stand site can directly affect the diameter and high growth of trees, site may also influence tree volume (Muhairwe et al., 1994). However, Eq. (15), as a variable taper equation that includes a stand density variable, can well predict diameters along the boles and to a certain extent, express the effect of stand density on stem tapers of Chinese fir trees.

Figure 6 is here.

\section{Conclusions}

Variable taper equations were developed for Chinese fir, the most important commercial tree species in southern China. The Sharma/Oderwald, Sharma/Zhang, and modified Brink's equations are superior to the Pain/Boyer equation in terms of the fitting and validation statistics.

The modified Brink's equation only had lower prediction precision than the Sharma/Oderwald and Sharma/Zhang equations at the butt diameter. If the final choice must be made, the modified Brink's equation and Sharma/Zhang equation are recommended for use as a taper equation for Chinese fir.

Correlation analysis results showed that stand planting density had an obvious effect on some parameters of taper equations. Therefore, the relationships between some parameters of the three selected equations and stand planting densities can be built by adopting some simple mathematical functions to examine the effect of stand planting density on tree taper.

The prediction precision of the three taper equations was compared with or without 
311 incorporation of the stand density variable. The M.D., A.M.D., and S.E.E. using for estimating

312 diameters along the stems for the validation data sets showed that adding the stand density

313 variable improved the evaluation efficacy of the taper equations for Chinese fir trees. The

314 maximum mean absolute bias of the modified Brink's and Sharma/Zhang equations with a stand

315 density variable were all below $1.0 \mathrm{~cm}$ in the study area. The modelling difference of tree

316 profiles among different stand densities mainly appeared below the $10 \%$ of total high.

\section{Acknowledgements}

Thanks go to Mr Quang V. Cao in the Louisiana State University for his help with revising and 


\section{References}

Bi, H., Trigonometric variable-form taper equations for Australian eucalypts. Forest Science, 2000, 46:397409.

Bi, H., and Turner, J., Long-term effects of superphosphate fertilization on stem form, taper and stem volume 
estimation of Pinus radiata. For. Eco. Mange., 1994, 70: 285 - 297.

Brink, C., and Gadow, K.V., On the use of growth and decay functions for modeling stem profiles. EDV in Medizin Biologie, 1986, 17, 20-27.

Brook, J.R., Jiang, L.C., and Ozcelik, R., Compatible stem volume and taper equations for Brutian pine, Cedar of Lebanon, and Cilicica fir in Turkey. For. Ecol. Manag., 2008, 256, 147-151.

Burkhart, H.E., and Walton, S.B., Incorporating crown ratio into taper equations for loblolly pine trees. For. Sci., 1985, 31:478-484.

Clark, A.C., Souter, R.A. and Schlaegel, B.E., Stem profile equations for southern tree species. US For. Serv. Southe. Res. Pap. SE-282. US For. Serv., Asheville, NC., 1991, 113p.

Cao, Q.V., and Wang, J., Calibrating fixed- and mixed-effects taper equations. For. Ecol. Mgt.,2011,262:671673.

Duan, A.G., Zhang, J.G. Zhang, X.Q., and He, C.Y., Stand Diameter Distribution Modelling and Prediction Based on Richards Function. PLoS ONE, 2013, 8(4): e62605.

Gadow, K.V., and Hui, G.Y., Modelling forest development. Kluwer Academic Publishers, 1999.

Gray, H.R., The form and taper of forest-tree stems. Imperial Forest Institute. Oxford, UK., 1956, 32p.

Gregoire, T.G., Schabenberger, O,, and Barrett, J.P., Linear modelling of irregularly spaced, unbalanced, longitudinal data from permanent-plot measurements. Can. J. For. Res., 1995, 25, 137-156.

Kozak, A., A variable-exponent taper equation. Can. J. For. Res., 1988, 18, 1363-1368.

Kozak, A., Effects of multicollinearity and autocorrelation on the variable-exponent taper functions. Can. J. For. Res., 1997, 27, 619-629.

Kozak, A., My last words on taper equations. Forestry Chronicles, 2004, 80(4): 507-515. 
374 Kozak, A., Munro, D.D., and Smtth, J.H.G., Taper functions and their application in forest inventory. For.

$375 \quad$ Chron, 1969, 45, 278-283.

376 Max, T.A., and Burkhart, H.E., Segmented polynomial regression applied to taper equations. For. Sci., 1976, 22, 283-289.

Myer R.H., Classical and modern regression with applications, $2^{\text {nd }}$ edn. Duxbury Press, Belmont, 1990.

Muhairwe, C.K., Taper equations for Eucalyptus pilularis and Eucalyptus grandis for the north coast in New South Wales, Australia. For. Ecol. Manag., 1999, 113, 251-269.

Muhairwe, C.K., Lemay, V.M., and Kozak, A., Effects of adding tree, and site variables to Kozak's variableexponent taper equation. Can. J. For. Res., 1994, 24, 252-259.

Myers, R.H., Classical and modern regression with applications, 2nd edn. Duxbury Press, Belmont, 1990.

Newberry, J.D., and Burkhart, H.E., Variable-form stem profile models for loblolly pine. Can. J. For. Res., $1986,16,109-114$.

Newnham, R.M., Variable-form taper functions for four Alberta tree species. Can. J. For. Res., 1992, 22, 210223.

Pain, O., and Boyer, E., A whole individual tree growth model for Norway spruce. Workshop IUFRO S5, 1996,

Palma, A., Influência da idade na forma do perfil do tronco em Pinheiro Bravo (Pinus pinaster Aiton). Dunas do litoral portugués. Silva Lusitana, 1998,6(2):161-194. 01-04-Topic 1.

Özçelik, R, Diamantopoulou, M.J., and Brooks, J.R., The use of tree crown variables in over-bark diameter 
and volume prediction models. iForest, 2014, 7: 132-139

Reed, D.D., and Byrne, J.C., A simple, variable form volume estimation system. For. Chron., 1985, 61, 87-90.

Riemer, T., Gadow, K.V., and Sloboda, B., Ein model zur beschreibung von Baumschäften. Allg. Forst. Jagdztg., 1995, 166(7): 144-147.

Rojo, A., Perales, X., Rodríguez, F.S., González, J.G.A., and Gadow, K.V., Stem taper functions for maritime pine (Pinus pinaster Ait.) in Galicia (Northwestern Spain). Eur. J. For. Res., 2005, 124, 177-186.

SAS, I., SAS/STAT 9.2 user's guide. Inc. Cary. Nc., 2008.

SFA., Reports of Chinese forestry resource: the 7th national forest resource inventory. Beijing, Chinese Forestry Publishing House, 2009.

Sharma, M., and Oderwald, R.G., Dimensionally compatible volume and taper equations. Can. J. For. Res., 2001, 31, 797-803.

Sharma, M., and Parton, J., Modeling stand density effects on taper for Jack pine and Black spruce plantations using dimensional analysis. For. Sci., 2009, 55(3):268-282.

Sharma, M., and Zhang, S.Y., Variable-exponent taper equations for jack pine, black spruce, and balsam fir in eastern Canada. For. Ecol. Manag., 2004, 198, 39-53.

Valenti, M.A., and Cao, Q.V., Use of crown ratio to improve loblolly pine taper equations. Can. J. For. Res. , 1986, 16:1141-1145.

Zhou, B.Z., Gu, L.H., Ding, Y.H., Shao, L., Wu, Z.M., Yang, X.S., Li, C.Z., Li, Z.C., Wang, X.M., Cao, Y.H., Zeng, B.S., Yu, M.K., Wang, S.K., Duan, A.G., An, Y.F., Wang, X., and Kong, W.J., The great 2008 chinese ice storm: its socioeconomic-ecological impact and sustainability lessons learned. Amer. Meteor. Soc., $\quad 2011,92,47-60$. 


\section{$421 \quad$ Figure legend:}

422 Figure 1 Tree diameter plotted against relative height with a cubic spline soothing curve

423 Figure 2 The error structure of Eq.(5) with or without random subject effects incorporated

424 Figure 3 The observed stem taper and tree profiles generated using Equation 2, 4 and 5 for a Chinese fir tree with the diameter at breast height $(15.4 \mathrm{~cm})$ and total height $(15.5 \mathrm{~m})$

Figure 4 Bias of taper prediction at relative height for Eqs.(2-6) using validation data sets.

Figure 5 The correlativities between some parameters of Eqs.(2) and (4) and stand planting densities

Figure 6 Tree profiles generated from Eq.(15) using $D=11.0 \mathrm{~cm}$ and $H=12.0 \mathrm{~m}$ at different densities

profiles below 0.1 at four different densities.

431

432

433

434

435

436

437

438

439

440

441

442

443

444 


\section{Table $\mathbf{1}$ (on next page)}

Table1

Summary statistics for total height and dbh of Chinese fir trees used in this study 
1 Table 1

2 Summary statistics for total height and dbh of Chinese fir trees used in this study

\begin{tabular}{|c|c|c|c|c|c|}
\hline Plant density (stems/ha) & Number of trees & Mean height $(\mathrm{m})$ & S.D. & Mean dbh $(\mathrm{cm})$ & S.D. \\
\hline \multicolumn{6}{|l|}{ Fit data } \\
\hline B: $3333(2 \times 1.5 \mathrm{~m})$ & 30 & 13.49 & 2.42 & 12.52 & 2.61 \\
\hline $\mathrm{C}: 5000(2 \times 1 \mathrm{~m})$ & 48 & 12.85 & 2.29 & 11.03 & 2.48 \\
\hline D: $6667(1 \times 1.5 \mathrm{~m})$ & 54 & 12.02 & 1.90 & 10.26 & 2.10 \\
\hline E: $10000(1 \times 1 \mathrm{~m})$ & 51 & 11.83 & 2.86 & 9.62 & 2.09 \\
\hline \multicolumn{6}{|l|}{ Validation data } \\
\hline B: $3333(2 \times 1.5 \mathrm{~m})$ & 20 & 13.91 & 2.14 & 12.94 & 2.48 \\
\hline $\mathrm{C}: 5000(2 \times 1 \mathrm{~m})$ & 30 & 13.25 & 2.14 & 11.47 & 2.06 \\
\hline D: $6667(1 \times 1.5 \mathrm{~m})$ & 30 & 12.33 & 1.76 & 10.47 & 1.92 \\
\hline E: $10000(1 \times 1 \mathrm{~m})$ & 30 & 11.93 & 1.84 & 9.30 & 1.74 \\
\hline
\end{tabular}

3 S.D. indicates standard deviation.

4

5 
Table 2 (on next page)

Table 2

Values of the estimated parameters and fit statistics for Eqs. (2-6) fit to taper data for all of the 183 trees (ns means not significance at the $95 \%$ level) 
$1 \quad$ Table 2

2 Values of the estimated parameters and fit statistics for Eqs. (2-6) fit to taper data for all of

3 the 183 trees (ns means not significance at the $95 \%$ level)

\begin{tabular}{ccccccccccccc}
\hline Model & $b_{1}$ & $b_{2}$ & $b_{3}$ & $b_{4}$ & $b_{5}$ & $b_{6}$ & $b_{7}$ & $b_{8}$ & $b_{9}$ & $p$ & $R_{a d j .}^{2}$ & S.E.E. \\
\hline Eq.(2) & 1.6318 & -0.0294 & 0.9428 & & & & & & & & 0.9649 & 0.6629 \\
Eq.(3) & 9.5276 & -0.3199 & & & & & & & & & 0.6952 & 1.9540 \\
Eq.(4) & 2.0307 & & & & & & & & & & 0.9772 & 0.5335 \\
Eq.(5) & 0.9964 & 2.0294 & -0.0302 & 0.1051 & & & & & & & 0.9782 & 0.5224 \\
Eq.(6) & 1.2327 & 0.9968 & ns & 0.2408 & ns & 0.5006 & -0.4297 & ns & ns & $\approx 0$ & 0.9785 & 0.5194 \\
\hline
\end{tabular}

4 
Table 3(on next page)

Table 3

Parameter estimates (standard errors in parentheses) and fit statistics for Eqs. $(2,4-5)$ while fitting the density-grouped subsets data using nonlinear regression (ns means not significant at the $95 \%$ level) 
1 Table 3

2 Parameter estimates (standard errors in parentheses) and fit statistics for Eqs. $(2,4-5)$ while

3 fitting the density-grouped subsets data using nonlinear regression (ns means not

4 significance at the $95 \%$ level)

\begin{tabular}{|c|c|c|c|c|c|}
\hline & \multirow{2}{*}{ Parameter } & \multicolumn{4}{|c|}{ Planting density (stems/ha) } \\
\hline & & 3333 & 5000 & 6667 & 10000 \\
\hline \multirow[t]{5}{*}{ Eq.(2) } & $b_{1}$ & $2.1568(0.1928)$ & $1.5143(0.1079)$ & $1.6975(0.1371)$ & $1.4346(0.0984)$ \\
\hline & $b_{2}$ & $0.0011(0.0094)$ & $-0.0436(0.0069)$ & $-0.0243(0.0097)$ & $-0.0392(0.0078)$ \\
\hline & $b_{3}$ & $0.6400(0.0781)$ & $1.2003(0.1722)$ & $0.8462(0.0963)$ & $1.1461(0.1409)$ \\
\hline & $R_{a d j}^{2}$ & 0.9761 & 0.9541 & 0.9653 & 0.9635 \\
\hline & S.E.E. & 0.6455 & 0.8007 & 0.6236 & 0.6009 \\
\hline \multirow[t]{3}{*}{ Eq.(4) } & $b_{1}$ & $2.0324(0.0015)$ & $2.0319(0.0013)$ & $2.0303(0.0010)$ & $2.0278(0.0011)$ \\
\hline & $R_{a d j}^{2}$ & 0.9815 & 0.9713 & 0.9810 & 0.9765 \\
\hline & S.E.E. & 0.6161 & 0.6198 & 0.4565 & 0.4768 \\
\hline \multirow[t]{6}{*}{ Eq.(5) } & $b_{1}$ & $0.9976(0.0077)$ & $0.9893(0.0085)$ & $0.9998(0.0064)$ & $0.9973(0.0074)$ \\
\hline & $b_{2}$ & $2.0280(0.0015)$ & $2.0326(0.0016)$ & $2.0293(0.0012)$ & $2.0273(0.0014)$ \\
\hline & $b_{3}$ & $\mathrm{~ns}$ & ns & $-0.0712(0.0347)$ & ns \\
\hline & $b_{4}$ & $0.1625(0.0509)$ & $0.0557(0.0551)$ & $0.1561(0.0443)$ & $0.0741(0.0513)$ \\
\hline & $R_{a d j}^{2}$ & 0.9848 & 0.9712 & 0.9817 & 0.9769 \\
\hline & S.E.E. & 0.4978 & 0.6180 & 0.4426 & 0.4724 \\
\hline
\end{tabular}

5

6 
Table 4(on next page)

Table 4

Parameter estimates (standard errors in parentheses) and fit statistics for Eqs. (13-15) using fit data sets 
$1 \quad$ Table 4

2 Parameter estimates (standard errors in parentheses) and fit statistics for Eqs. (13-15)

3 using fit data sets

\begin{tabular}{ccccc}
\hline & Parameter & Estimates of parameters & S.E.E. & $R_{\text {adj. }}^{2}$ \\
\hline Eq.(13) & $i_{1}$ & $2.1504(0.5675)$ & 0.6627 & 0.9650 \\
& $i_{2}$ & $-0.0306(0.0292)$ & & \\
& $b_{2}$ & $-0.0282(0.0040)$ & & \\
& $b_{3}$ & $0.9331(0.0575)$ & & \\
Eq.(14) & $k_{1}$ & $21.7021(8.5436)$ & 0.5327 & 0.9773 \\
& $k_{2}$ & $2.0266(0.0017)$ & & \\
Eq.(15) & $b_{1}$ & $0.9964(0.0039)$ & 0.5219 & \\
& $b_{2}$ & $2.0257(0.0017)$ & & \\
& $b_{3}$ & $-0.0310(0.0204)$ & & \\
& $b_{4}$ & $0.1058(0.0259)$ & & \\
& $b_{5}$ & $19.6487(8.3747)$ & & \\
\hline
\end{tabular}

4 
Table 5(on next page)

Table 5

Bias $(\mathrm{cm})$ and absolute bias $(\mathrm{cm})$ in predicting diameters along the bole of Chinese fir trees for Eqs. (13-15) (with stand density variable) using validation data sets 
1 Table 5

2 Bias (cm) and absolute bias (cm) in predicting diameters along the bole of Chinese fir trees

3 for Eqs. (13-15) (with stand density variable) using validation data sets

\begin{tabular}{|c|c|c|c|c|c|c|c|}
\hline \multirow{2}{*}{ Relative height } & \multirow{2}{*}{ Number } & \multicolumn{3}{|c|}{ Bias $(\mathrm{cm})$} & \multicolumn{3}{|c|}{ Absolute bias (cm) } \\
\hline & & Eq.(13) & Eq.(14) & Eq.(15) & Eq.(13) & Eq.(14) & Eq.(15) \\
\hline $0.0 \leq \mathrm{h} / \mathrm{H} \leq 0.1$ & 279 & 0.7662 & 0.0233 & 0.0829 & 0.7835 & 0.3214 & 0.3250 \\
\hline $0.1<\mathrm{h} / \mathrm{H} \leq 0.2$ & 205 & -0.0226 & -0.0185 & -0.0053 & 0.1164 & 0.1170 & 0.1228 \\
\hline $0.2<\mathrm{h} / \mathrm{H} \leq 0.3$ & 157 & -0.0215 & -0.0453 & -0.0379 & 0.1962 & 0.2054 & 0.2048 \\
\hline $0.3<\mathrm{h} / \mathrm{H} \leq 0.4$ & 151 & -0.0297 & -0.0984 & -0.0757 & 0.2683 & 0.2780 & 0.2745 \\
\hline $0.4<\mathrm{h} / \mathrm{H} \leq 0.5$ & 151 & 0.0414 & -0.0795 & -0.0237 & 0.3138 & 0.3089 & 0.3043 \\
\hline $0.5<\mathrm{h} / \mathrm{H} \leq 0.6$ & 153 & 0.0976 & -0.0598 & 0.0454 & 0.3910 & 0.3662 & 0.3656 \\
\hline $0.6<\mathrm{h} / \mathrm{H} \leq 0.7$ & 154 & 0.1041 & -0.0419 & 0.1170 & 0.4514 & 0.4164 & 0.4360 \\
\hline $0.7<\mathrm{h} / \mathrm{H} \leq 0.8$ & 160 & 0.0624 & -0.0564 & 0.1513 & 0.4992 & 0.4817 & 0.5161 \\
\hline $0.8<\mathrm{h} / \mathrm{H} \leq 0.9$ & 152 & -0.0556 & -0.2528 & -0.0177 & 0.4773 & 0.5498 & 0.5106 \\
\hline $0.9<\mathrm{h} / \mathrm{H} \leq 1.0$ & 139 & 0.2573 & -0.2779 & -0.0983 & 0.4725 & 0.5370 & 0.4635 \\
\hline
\end{tabular}

4 
Table 6(on next page)

Table 6

Values of the statistics in the validation step for Eqs. $(2,4-5)$ with and without the density variable in the model ody 
1 Table 6

2 Values of the statistics in the validation step for Eqs. $(2,4-5)$ with and without the density

3 variable in the model

\begin{tabular}{cccccccc} 
& \multicolumn{2}{c}{ Equations with stand density variable } & & \multicolumn{3}{c}{ Equations without stand density variable } \\
\cline { 2 - 4 } \cline { 5 - 7 } Statistics & Eq.(13) & Eq.(14) & Eq.(15) & & Eq.(2) & Eq.(4) & Eq.(5) \\
M.D. & 0.1601 & -0.0752 & 0.0223 & & 0.1612 & -0.0758 & 0.0226 \\
M.A.D. & 0.4155 & 0.3452 & 0.3416 & & 0.4157 & 0.3453 & 0.3418 \\
S.E.E. & 0.6543 & 0.5007 & 0.4835 & & 0.6548 & 0.5011 & 0.4838 \\
\hline
\end{tabular}

4 


\section{Figure 1 (on next page)}

Figure 1 Tree diameter plotted against relative height with a cubic spline soothing curve and sta

Figure 1 Tree diameter plotted against relative height with a cubic spline soothing curve and sta 


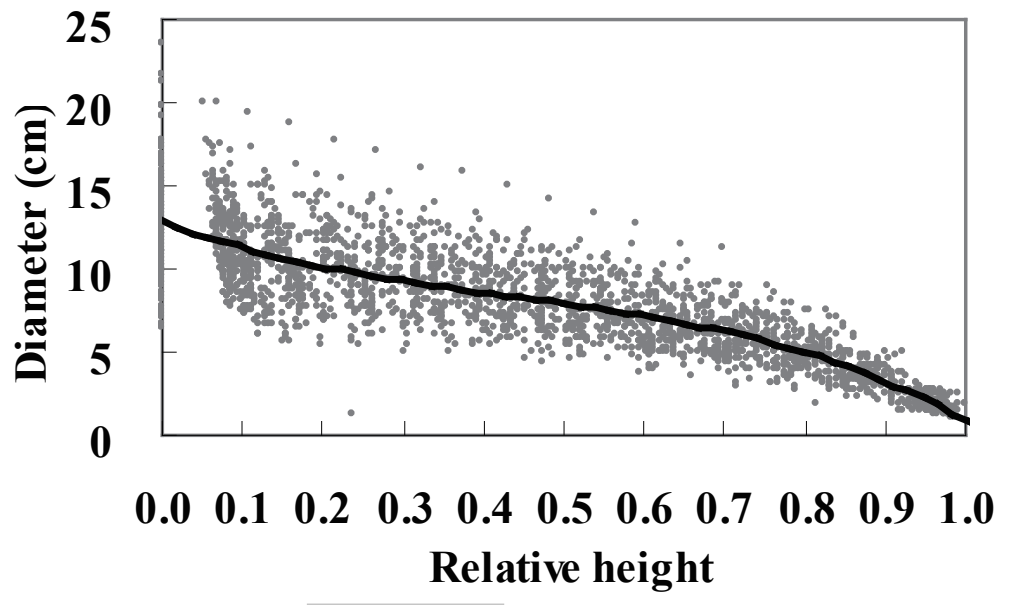




\section{Figure 2 (on next page)}

Figure 2

Figure 2 The error structure of Eq.(5) with or without random subject effects incorporated 


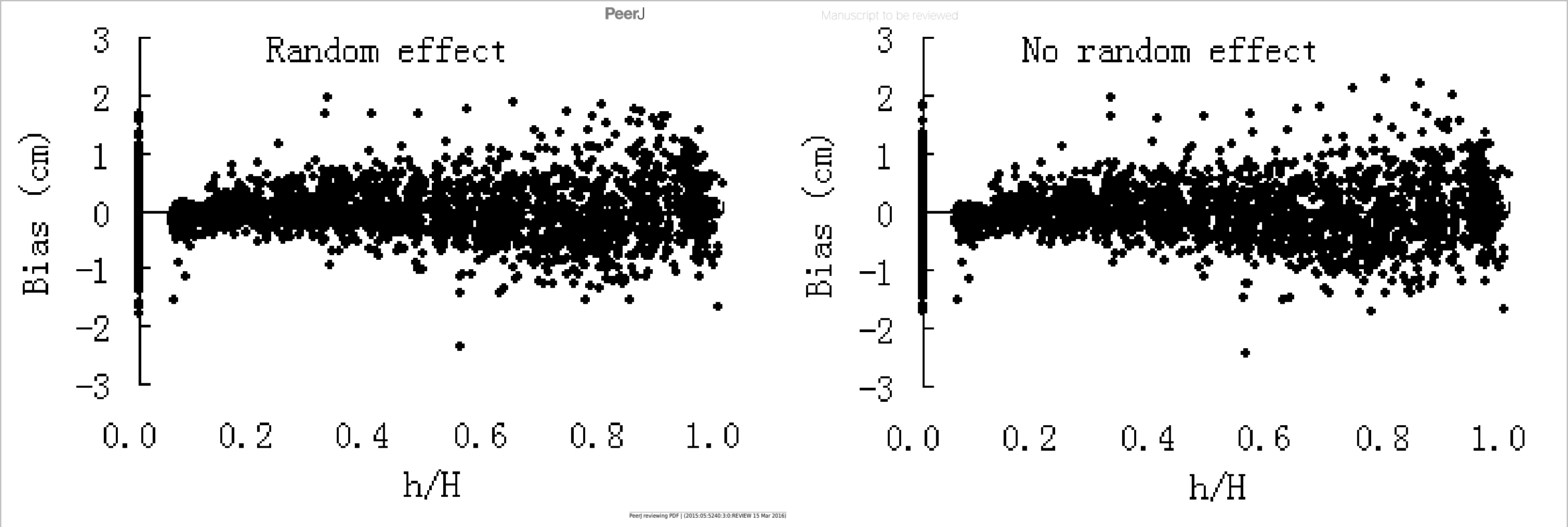




\section{Figure 3 (on next page)}

Figure 3

The observed stem taper and tree profiles generated using Equation 2, 4 and 5 for a Chinese

fir tree with the diameter at breast height $(15.4 \mathrm{~cm})$ and total height $(15.5 \mathrm{~m})$ 


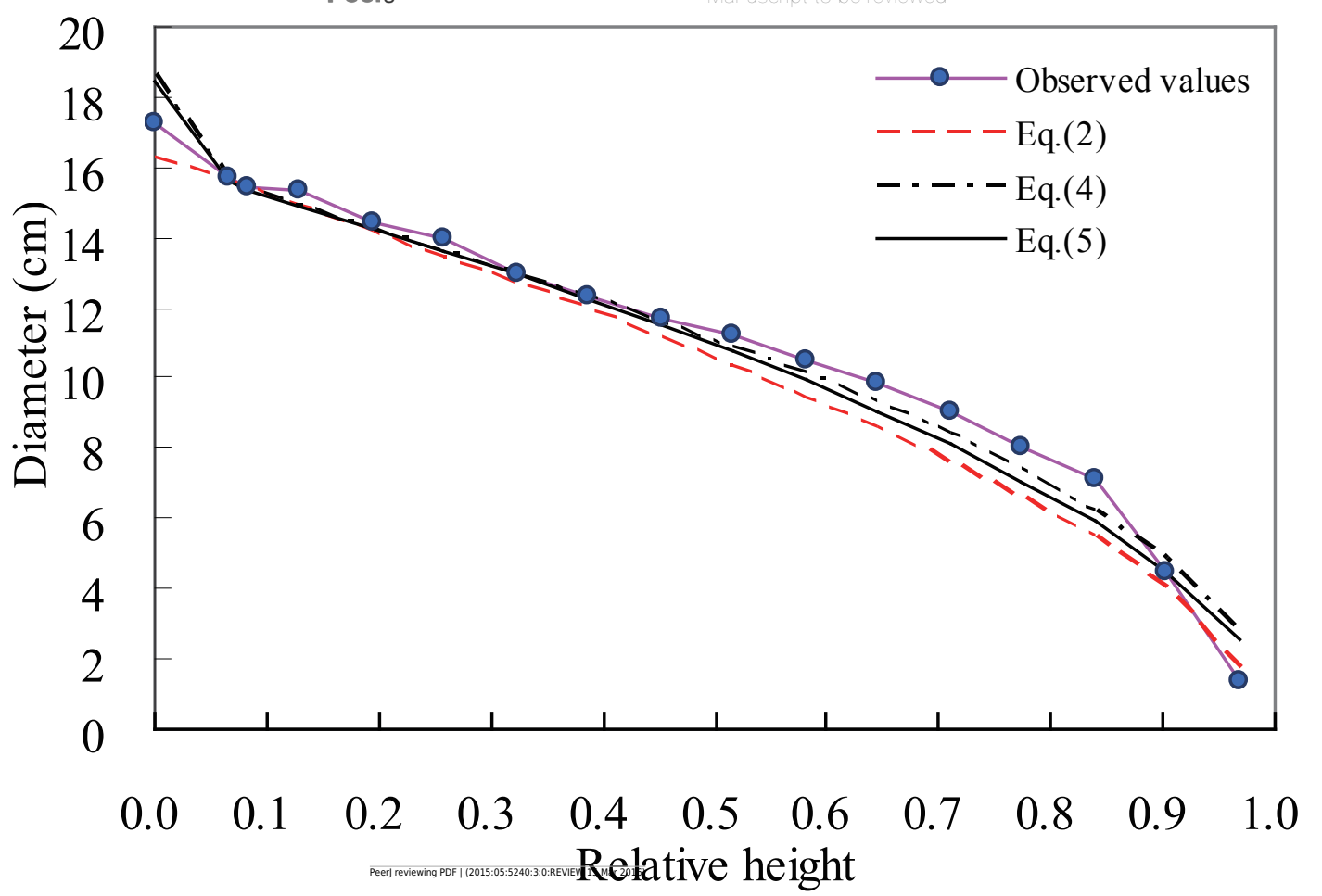




\section{Figure 4 (on next page)}

Figure 4

Bias of taper prediction at relative height for Eqs.(2-6) using validation data sets 

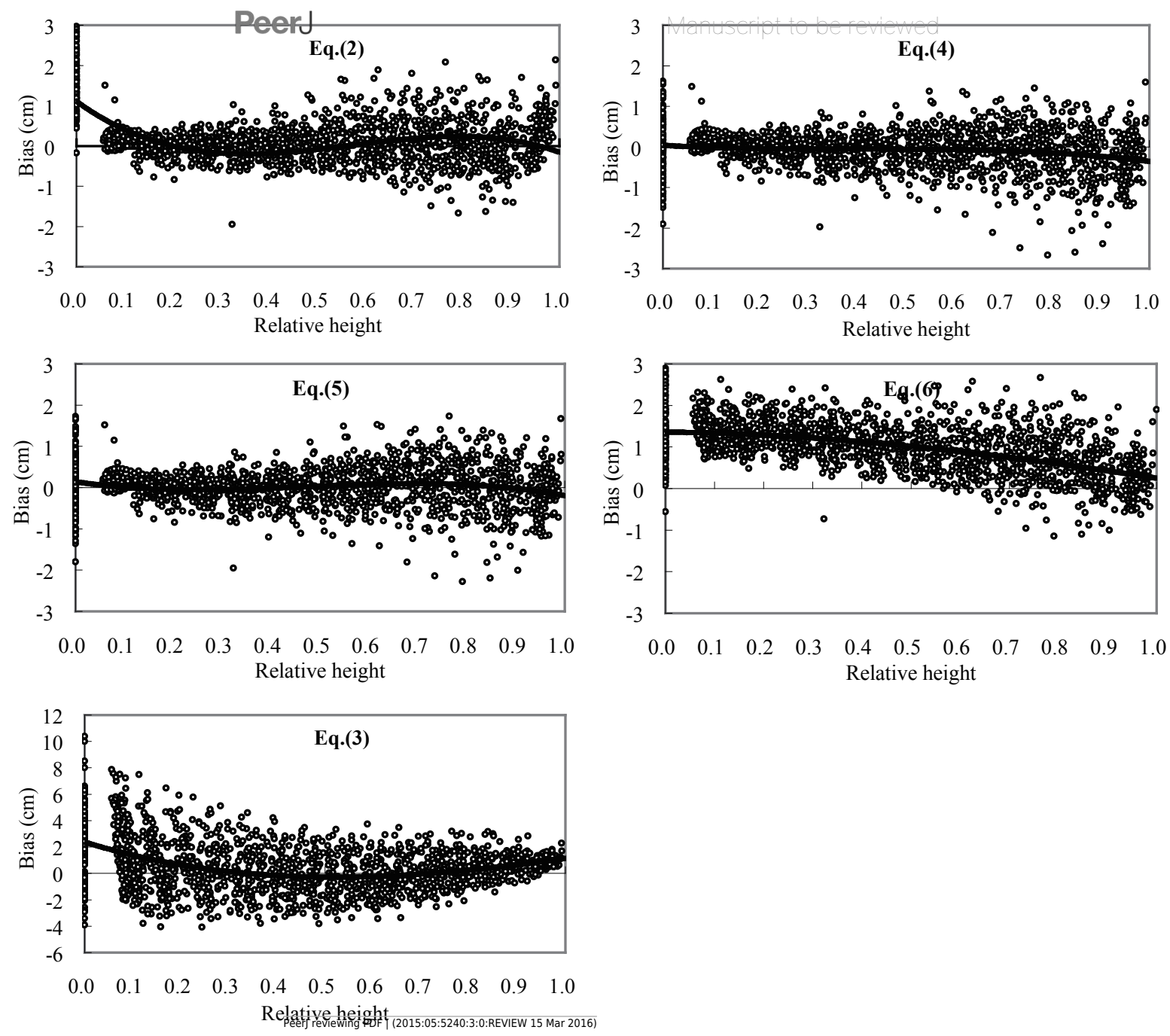
Figure $\mathbf{5}$ (on next page)

The correlativities between some parameters of Eqs.(2) and (4) and stand planting densities .5pt; $q$

The correlativities between some parameters of Eqs.(2) and (4) and stand planting densities .5pt; q 
Figure 6 (on next page)

Tree profiles generated from Eq.(15) using $\mathrm{D}=11.0 \mathrm{~cm}$ and $\mathrm{H}=12.0 \mathrm{~m}$ at different densities (1000, 2000, 3000 and 4000 trees/ha) for Chinese fir.

Tree profiles generated from Eq.(15) using $D=11.0 \mathrm{~cm}$ and $\mathrm{H}=12.0 \mathrm{~m}$ at different densities (1000, 2000, 3000 and 4000 trees/ha) for Chinese fir. 
